\title{
Relationship Between Enablers and Barriers to Financial Inclusion - the Case of North Macedonia
}

\author{
Natasha Eftimovska \\ University for Peace established by the United Nations, European Centre for Peace and \\ Development (ECPD), Terazije 41, Belgrade, Republic of Serbia \\ E-mail: eftimovska_natasa@yahoo.com
}

Received: February 25, 2021

doi:10.5296/ifb.v8i1.18349
Accepted: May 19, $2021 \quad$ Published: June 15, 2021

URL: http://dx.doi.org/10.5296/ifb.v8i1.18349

\begin{abstract}
This research aims to examine the relationship between factors that act as enablers or barriers to financial inclusion, as independent variables, and the environment for financial inclusion, as a dependent variable, for the case of North Macedonia. For accomplishing the main research objective, first, the factors that act as enablers or barriers to financial inclusion were identified by collecting primary data using questionnaires and performing comparative analysis on our country's position with different regions categorized by income groups and World, through the benchmarking model of Global Microscope (Economist Intelligence Unit, 2018. Global Microscope 2018. The Enabling Environment for Financial Inclusion. The EIU, The Economist). Second, primary data from questionnaires served to furtherly examine the correlation between each identified enabler or barrier to financial inclusion and the overall environment for financial inclusion through multiple regression analysis. Results revealed important information and recommendations for the future focus of national priorities, institutional arrangements, policies, and strategies in terms of creating enabling environment for financial inclusion, benefits of which can be felt by the overall society.
\end{abstract}

Keywords: financial inclusion, enablers, barriers, correlation, fintech, digitalization, North Macedonia 


\section{Introduction}

\subsection{Problem Statement}

The rapid development of financial technology through various innovations in the financial services market opens significant space for higher financial inclusion which is a top priority of each government today. However, even though almost 70 percent of all adults are financially included, still almost 1.7 billion globally lack access to formal financial services, which directly affects economic growth.

Our country, as part of the global economy also puts the fin-tech agenda on the front foot, by creating a legal framework in line with European legislation for financial services, as a first step towards creating an environment that encourages digitalization and innovation, opens the market for new players in the field of financial services, fostering competition and expecting to achieve higher financial inclusiveness.

Currently, the level of financial inclusion for our country is measured within several international survey frameworks, such as the Global Findex survey (Asli et al., 2018) as the most comprehensive database for measuring the access to and use of financial services and the Financial Access Survey (IMF, 2019), as a unique supply-side annual global database for the access to and use of basic financial services, as well as through the national payment statistics database (National Bank of the Republic of North Macedonia, 2020). However, currently, there is no study for our country examining the environment for financial inclusion in terms of the regulatory and policy environment for financial inclusion, as introduced by the Global Microscope Report 2018 (EIU, 2018), which goes beyond just measuring the access and use of financial services, by setting up a benchmarking model for assessment of the enabling environment for financial inclusion.

This research aims to examine the relationship between factors that act as enablers or barriers to financial inclusion, as independent variables, and the environment for financial inclusion, as a dependent variable. The first additional research objective arising from the main objective is examining the factors determining the environment for financial inclusion in North Macedonia through the proposed questionnaire framework of EIU (2018) resulting in the identification of the factors that act as enablers or barriers to financial inclusion, utilized to perform a comparative survey on our country's position in relation with different regions categorized by income groups and World, by building on the benchmarking model within the Global Microscope 2018 (EIU, 2018). Findings from questionnaires served to achieve the second additional research objective by furtherly examining the correlation between each identified enabler or barrier to financial inclusion and the overall environment for financial inclusion through multiple regression analysis.

Findings provided significant information for main enablers and barriers to the environment for financial inclusion as well as factors that have the highest influence on the environment of financial inclusion in our country, being important signals for the future activities of relevant stakeholders leading to enabling environment for financial inclusion.

The rest of the research is structured as follows: Section 2 introduces the methodology used 
for achieving the main and additional research objectives, Section 3 presents the results and Section 4 provides the conclusions and discussion.

\subsection{Importance of the Problem, Rationale, and Significance of the Research Study}

On a national level, even the international surveys and the national payments statistics provide some quantitative data on the level of financial inclusion, there is no research study examining the factors behind that act as enablers or barriers to the environment for financial inclusion revealing the reasons why each quantitative indicator is measured on a low or high level. In addition, the current literature doesn't cover a research study furtherly examining the relationship and dependence between the factors that act as enablers or barriers and the overall environment for financial inclusion in our country, bearing its national specifics, as well as the stage of development of an environment for financial inclusion for our country in comparison with other countries and regions. This research study shall try to overlap these data gaps in the present literature review, and is expected to give significant theoretical as well as a practical contribution to the current research database by enriching the available data for the specific case of North Macedonia, its position, and future perspectives in the financial inclusion landscape on the world map.

\subsection{Literature Review}

\subsection{1 "Fintech" - as One of the Main Prerequisites for Achieving Higher Financial Inclusion}

Although 'fintech' is a relatively new term, technology has always been important in the financial sector, where the key difference now is the pace and impact of change across the financial system which has increased markedly over the past decade, as recognized by EY (2017). According to the Biannual global analysis of investment in fintech of KPMG (2019), Fintech investment increased substantially in 2018, more than doubling from $\$ 50.8$ billion in 2017 to $\$ 111.8$ billion in 2018 , and estimations are that there is likely to be an increase in future investment focused on solutions targeted to the needs of unbanked and underbanked people in the developing world, leading to higher financial inclusion.

The main drivers for the development of fintech can be observed from the supply and demand side. Kuroda (2016) has identified as drivers on the supply side, first of all, the advance in technological innovations related to information and communications, followed by the rapid growth of the processing power of computers that can analyze huge amounts of data, in a relatively short time, supplemented by the rapid spread of infrastructure forms as internet and mobile terminals which are easily accessible to a wide range of people, which can generate large expectations for penetration of new forms of financial services especially for emerging or developing nations. Also, the KPMG Analysis (2019) has recognized that open data is a driving factor for significant fintech developments, as open banking and open data continued to be key topics among fintech investors. Schindler (2017) has used the supply and demand framework of fintech developed by Kimbrough and Schindler (2014) to identify main drivers on the supply side, where he has expanded the factors noted by Kuroda (2016) to also include regulation, innovation spirals, and changes to the macroeconomic or financial landscape, besides technology and infrastructure. 
On the demand side, Kuroda (2016) has identified the globalization of the economy as the main driver for fintech development, because it stimulates more and more cross border transactions, which have encouraged the rise of new forms of economic activities such as "e-commerce" and the "sharing economy". Furthermore, besides "globalizing" fintech services, fintech may also facilitate "personalized" and "virtualized" financial services, as recognized by Nakaso (2016), giving an example with the cellphones and smartphones which have characteristics of "personalized" tools. Also, concerning the concept of "virtualizing" financial services, Nakaso (2016) referred to the traditional "brick \& mortar branches" and ATMs that may not be any more prerequisites for providing financial services; because access to the financial services can also be provided with the use of the internet, smartphones, cloud computing, AI and DLT. Making a parallel with the above-identified demand factors by Kuroda (2016), Schindler (2017) made an argument that financial institutions can offer an array of new products and services, but the products will fail if there is insufficient demand, where he stated that main demand factors that contribute to innovation are the demographics and again regulation, as on the supply side, explaining that the regulation can create a demand for a new product, but also demographics can be an important driver of the move toward the adoption of new product/service, such as the example with mobile financial services, where demographics is identified as the main driver for this innovation.

The Executive Board of IMF (2018) identified many opportunities arising from fintech, such as contributing to the reduction of costs and frictions, increasing efficiency and competition, narrowing information asymmetry, deepening and enhancing the efficiencies of financial systems, and broadening the access to financial services-especially in low-income countries and for underserved populations, which leads to broader economic development and inclusive growth.

Mnohoghitnei et al. (2019) also recognized many opportunities created by fintech, amongst which are the potential to help meet unfulfilled customer demands and ease frictions in financial services (for example with blockchain technology), arising from the ability to unbundle traditional financial services activities into core functions such as settling payments, performing maturity transformation, sharing risk and allocating capital. It is expected that open banking as a driver to fintech development will lead to more competition and be a catalyst for the development of partnerships that will allow fintech to grow (KPMG, 2019). Fintech also creates opportunities for regtech investments, where fintech could be used to improve the compliance processes at financial institutions, because regulation is increasing globally and the effective development and application of "regtech" could create opportunities to, for example, automate regulatory reporting and compliance requirements as well as facilitate more cross-sectoral and cross-jurisdictional cooperation for improved compliance, such as in AML/CFT (BIS, 2018).

However, the IMF Policy Paper (IMF, 2018) also stated the existence of many potential risks posed by rapid technological advances, such as threats to financial integrity, consumer protection, and financial stability, including regulatory compliance risks and global systemic risks, and therefore the need for adequate preparation and coordination by national authorities through the strengthening of institutional capacity, building up knowledge, improving 
communication with stakeholders, and expanding consumer education. Consequently, the advancement of fintech is a new challenge for the policymakers, since they should stimulate financial development and financial inclusion, as their final aim while maintaining these risks.

The fintech development benefits have a much stronger effect on Emerging Market Economies (EMEs) than for Advanced Economies. According to Pereira da Silva (2018), many factors are contributing to the rapid growth of fintech in EMEs in recent years: first, the financial systems that are less developed and efficient create more scope for new services, second, the lower degree of financial inclusion offers the potential of broader access, stating the example of around half of the adult population in most EMEs that is unbanked, compared with less than $10 \%$ in the Euro Area and the United States, and third, the increasing penetration of internet and mobile technologies provides a natural vehicle for fintech expansion. Development in mobile technology has stimulated rapid growth in the mobile phone-based banking and payment services in the EMEs, where banks started serving unbanked customers in remote areas via mobile devices through designated agents, and nonbanks, such as mobile operators have expanded the reach and range of their services, offering also banking services. The benefits of several other technologies for EME's are to be furtherly expected in the prospective future, like the distributed ledger technology (DLT) that forms the basis of cryptocurrencies such as bitcoin, but could have much broader applications (see e.g., Deshpande et al., 2017; World Bank, 2017). The potential use of DLT would be highly beneficial for cross-border remittances which are generally very costly, especially when the banks involved do not have a direct relationship and must work through correspondents (CPMI, 2016), and additionally with the cross-border bank transfers as well as traditional trade finance instruments, such as LC's. Machine learning (ML) and big data (BD) analytics offer also great perspectives for EME's. For example, some Chinese lenders are reportedly experimenting with $\mathrm{ML}$ and $\mathrm{BD}$ to screen online borrowers and improve credit scoring and risk management, as stated by Pereira da Silva (2018).

The fintech adoption rate is growing faster than anticipated, and the actual global adoption rate of $64 \%$ in 2019 exceeds by 12 points the 52\% future adoption rate predicted by the 2019 Report of EY (2019) led by the emerging markets.

1.3.2 Digitalization - as One of the Main Prerequisites for Achieving Higher Financial Inclusion

Digital technology is transforming the payments landscape. Mobile phones, computers, or cards used over point-of-sale (POS) devices connect individuals and businesses to a digitized national payments infrastructure, enabling seamless transactions across all parties.

Still, there is a high percentage of people and small businesses, especially in emerging economies today who do not fully participate in the formal financial system. The Report of McKinsey Global Institute (2016) on digital finance detected that there is still a large market segment that transacts exclusively in cash, have no safe way to save or invest money, and do not have access to credit beyond informal lenders and personal networks, and that even those with financial accounts may have only limited product choice and face high fees. As a result, 
a significant amount of wealth is stored outside the financial system and credit is scarce and expensive, leading to a negative impact on economic growth.

Digital finance can offer a transformational solution and without the need for major investments of costly additional infrastructure. Digitalization strategies now focus not solely on payment instruments as such, but also on broader solutions that adopt the perspective on different payment segments (person-to-person, business-to-business, client-to-merchant, etc.), always taking care of the inclusive approach at service of the society (Banque De France, 2019).

The process of high digitalization can bring many benefits especially for emerging economies, and amongst most important identified by McKinzey Report (2016) are the following:

- Digital financial services can expand customers' access and the reach of providers, because of the increased use of mobile phones and higher quality of internet network coverage.

= Digital finance lowers the cost of providing financial services by 80 to 90 percent, as stated by Voorhies et al. (2016) that the cost of serving a customer using mobile-money accounts can be up to 80 to 90 percent lower than using physical branches, which creates enormous cost-efficiency. Savings arise from the cut of costs for creating and maintaining an account, processing payment transactions, and providing people with the ability to deposit and withdraw cash into accounts, such as the case in Kenya, where the number of users of the M-Pesa mobile-money system grew from zero to 40 percent of adults in just three years following its 2007 launch (Mas \& Radcliffe, 2011).

- Digital payments enable penetration of new business models and revenue streams, such as:

a) New types of financial services as mobile payment networks grow and leave data trails,

b) Micropayments which create new business models, such as micropayments intended for schools, utilities, etc.,

c) Digital payments enable e-commerce channels as well as on-demand services and "sharing economy" markets such as ride-sharing and employment matching (McKinzey Report, 2016)

The process of digitalization also is expected to have long-term effects on growth and living standards and an increase in GDP. These broader benefits will contribute to progress toward meeting United Nations sustainable development goals for 2030 (UN, 2018):

- Raising the quality and quantity of health care and education, leading to improved human capital.

- Reducing the informal economy. 
- Enhancing liquidity.

- Promoting innovation and new business formation.

To fully capture the potential benefits form digitalization, the following three elements of "building blocks" are required to be established by the government leaders and business (McKinzey, 2016):

\section{1) Building a widespread digital infrastructure.}

Concerning this precondition, three primary components are required: mobile connectivity and ownership, digital-payment infrastructure, and widely accepted personal IDs.

\section{2) Establishing dynamic and sustainable markets for financial service providers.}

Although widespread digital infrastructure lays a foundation, a sustainable and competitive business environment is then required for a broad range of participants in digital finance, including not only banks, but also telecom companies, mobile handset manufacturers, fintech startups, and other businesses such as those in retail. The McKinzey (2016) Report determined two important aspects: implementing risk-proportionate regulation that promotes a stable financial system in which the interests of providers and users are aligned and fostering innovation and competition.

\section{3) Offering a wide choice of products that enable choosing a product that people prefer most}

Digitalization of financial services needs to offer various alternatives to consumers enabling choices that best suits the needs of the consumer.

However, the McKinsey report (McKinsey, 2016) stated that achieving a digital future will be a long process and in the immediate term, digital finance will coexist with cash and with the use of physical cards. Even in advanced economies, such as Norway, which has the world's highest share of digital payments, 22 percent of transactions are still conducted in cash and in the United States, where around 38 percent of transactions run over card payment networks, four in five of these payments are still made with a physical card present (McKinsey, 2016).

\subsection{Main and Additional Research Objectives}

This research aims to examine the relationship between factors that act as enablers or barriers to financial inclusion, as independent variables, and the environment for financial inclusion, as a dependent variable, as a basis for predicting future growth.

Referring to the main research objective, the following additional research objectives derived:

- Assessment of the level of development of factors that acts as enablers or barriers to the environment for financial inclusion for North Macedonia compared with regions by the level of income and World,

- Examining the correlation between each enabler and barrier with the financial inclusion. 


\section{MlMacrothink}

\section{Research Methods}

\subsection{Research Design for 1st Research Objective}

The research model for achieving the first research objective was the benchmarking model of Global Microscope invented by the EIU (2018) providing a comparative analysis based on a developed questionnaire framework consisting of five domains of factors for assessing the environment for financial inclusion (each of them containing several subcategories of factors):

1) Government and Policy Support

2) Stability and Integrity

3) Products and Outlets

4) Consumer Protection

5) Infrastructure.

For this research, the questionnaire framework proposed within the benchmarking model of Global Microscope EIU (2018) was adopted and shortened by utilizing the questions relevant for this research, omitting questions for which there were secondary data sources providing results, or were not relevant for this research (ex. gender aspects), which were then summarized and utilized as a questionnaire for the assessment of the level of enabling environment for financial inclusion, also ensuring comparative analysis with other regions and World.

\subsubsection{Data Collection}

\section{- Structure of the questionnaire}

The design of the questionnaires was highly structured bearing in mind that the questionnaire instrument should be long enough to cover the essential elements of the research but not too long to be overly time-consuming for respondents (Rummel \& Ballaine, 1963). The questionnaires were at the open end of each section to leave space for additional comments also providing justifications for the final assigned score for each question.

Questionnaires were designed by grouping the questions into two parts: Part I-Introductory questions and Part II-Factors that determine the environment for financial inclusion. Part I of the questionnaires (6 questions) used classification or category questions (age group, educational background, working experience, etc.) which can serve for easier grouping and comparing results from behavioral and attitudinal questions. Part II of the questionnaires (46 questions) assessed the level of development of each domain factor, where high developed factors were determined as enablers while low developed factors as barriers to financial inclusion.

The first domain, Government and Policy Support, assessed the level of governmental coordination and incentives for the creation of a favorable environment for financial inclusion. The second domain, Stability, and Integrity, assessed the overall regulation, supervision, and 
monitoring of financial services providers to ensure prudential stability and financial integrity. The third domain, Products, and Outlets examined the regulation of specific products and outlets that reach low- and middle-income populations. The fourth, Consumer Protection, evaluated consumer protection and privacy regulation and enforcement. The fifth domain, Infrastructure, examined the digital, identification, and credit reporting infrastructures that facilitate financial inclusion.

Questionnaires were structured by providing alternative answers to each question, using scoring for each response, according to predefined scoring criteria.

The benchmarking model of Global Microscope (EIU, 2018) providing results for 55 countries worldwide, was used to compare results on a national level to results for the same group of factors for the 55 countries grouped in regions by income group as well as on a World level, ensuring comparability and reliability of this research.

\section{- A sampling of the questionnaire}

The research population for the questionnaires had been carefully selected depending on the type of expertise and professional background of respondents which had to be closely connected with the topics of the questions investigated within each domain group (due to the very specific nature of the questions), by using heterogeneous purposive sampling by incorporating population directly involved with the topics investigated. Therefore it was expected that this target group of 20 respondents would provide very profound and quality responses ensuring high reliability of the findings from the results of the collected questionnaire.

\section{- Introducing the questionnaire}

The introduction of the questionnaire to the target group of respondents was done by previously informing the respondents about the aim of the research by sending a cover letter and providing their acceptance for participation.

\section{- $\quad$-Pilot testing}

Before sending the questionnaire to the targeted respondents, one pilot questionnaire was conducted to estimate if the questionnaire is understandable and easily approachable, as well as if the questionnaire flow is well modeled. After the respondent has confirmed that the questionnaire is interesting and understandable, and it takes only 15 minutes to fill it, the remaining questionnaires were sent by email to 20 targeted respondents.

\section{- Distributing the questionnaires}

Questionnaires were delivered to respondents by email, as a less time-consuming method and ensuring very fast return. For cases where feedback was not received within 1 week, the respondent was contacted by phone, to check if any of the questions need additional clarifications or if the respondent faced any other issues with replying to the questions. 


\subsubsection{Data Analysis}

Questionnaires' responses analysis was done following the scoring methodology of benchmarking model of the Global Microscope (EIU, 2018). First, the final score was allocated to each question based on the alternative selected by a majority of respondents for each response. To ensure the correctness of the finally chosen score behind each question, each respondent's response was reviewed thoroughly based on additional comments and explanations and the final score selected for each question was supported with written justification. In cases where additional data were needed to better understand the context around some of the scores that deviate from the majority of assigned score for a question, the researcher additionally contacted the respondents for getting their explanation supporting their response, which helped to finally determine the score behind each question based on respondents arguments and provided information.

After the final raw score was assigned to each question based on the questionnaire results, scores were normalized to a 0-100 range by using equal weights to each of the categories. Then, the overall scores were adjusted for the political risk factor reflecting a country's political environment, where the overall score could be reduced maximum up to $25 \%$ if a country had the worst possible political risk score. For more detailed information on the methodology, please refer to www.eiu.com/microscope 2018 (EIU, 2018).

\subsubsection{Ethical Considerations}

The ethical issues were prevailed by informing the participants about their right to confidentiality and anonymity, refusing to participate, or not to answer some questions.

\subsection{Research Design for 2nd Research Objective}

For examining the correlation between identified key enablers or key barriers and financial inclusion as a basis for forecasting growth of financial inclusion, the research model applied was the Causal research, more specifically "the cause and effect relationship", used for examining the relationships where a change in one or more independent variables causes a change in another (dependent) variable (Saunders et al., 2003). This research objective aims to assess the strength of relationship or dependence of the variable-environment for financial inclusion, as a dependent variable, from each of the independent variables (enablers and barriers to financial inclusion) influencing positively/or negatively/or not influence the financial inclusion.

For this purpose, a multiple regression analysis was performed for the five groups of independent variables identified within the Global Microscope framework, measured against the overall environment for financial inclusion, as a dependent variable.

\subsubsection{Data Sample}

The data used for the multiple regression analysis were the summarized scores of the 5 groups of independent variables applied for a sample of 56 countries representing countries from all income levels (High-Income countries, Upper-Middle Income countries, Lower-Middle Income countries, and Low-Income countries), including data scores for North 
Macedonia. The summarized data for 55 countries which was utilized for the model is available on www.eiu.com/microscope2018 (EIU, 2018), supplemented with data for North Macedonia coming from the questionnaire results.

\subsubsection{Research Method}

The Ordinary least squares (OLS) method is utilized for the multiple regression model to analyze the data to predict the variance of a dependent variable based on the changes in independent variables, by using the E-views tool. Although the multiple regression model when utilizing more independent variables can provide better predictions, it also has the danger to produce fewer quality predictions and distorts the results. Therefore, before choosing the best-fitting model, first, the existence of the potential problems of overfitting, multi-collinearity, and heteroscedasticity problems was examined.

The potential overfitting risk is caused by adding more independent variables which account for more variance in the model but do not add value to the model. Therefore, first, we need to examine the correlation between each independent variable and dependent variable and eliminate independent variables that have weak or no correlation and therefore do not contribute sufficiently to the dependent variable, and use only the non-redundant independent variables to find the best fitting model. To do this, scatterplots, correlation analysis, as well as simple linear regressions for each independent variable and dependent variable (for confirming the results of a scatterplot), were performed.

The potential multi-collinearity risk refers to situations in which two or more of the independent variables are highly correlated with each other, leading to the risk of not being sure which of the independent variables explains the variation in the dependent variable. (David et al., 2017) The potential multi-collinearity risk was examined through the Variance Inflation Factors (VIF's) which should be less than 5.0 according to the criteria developed by Snee (1973).

To check if there is a multi-collinearity issue in the full regression model, and choose the best fitting model for our predictions, multivariate regression analysis was conducted for the full model - Y (Financial inclusion) versus all independent variables X1, X2, X3, X4, X5.

The potential risk of heteroscedasticity, as a systematic change in the spread of residuals over the range of measured values, which could lead to inefficient regression predictions, was examined by plotting the sample residuals against the fitted values and see whether or not there is a "pattern" in them and if the plot looks like a cloud of random noise with no pattern, the assumption of homoscedasticity is likely, while If any kind of clustering or trend is detected, then the assumption is suspect and needs further assessment (Astivia et al., 2019) Also, the heteroscedasticity is being measured through the Breusch-Pagan-Godfrey heteroscedasticity test and the Jarque-Berra probability coefficient.

The ideal situation would be for all independent variables to be correlated with the dependent variable but not with each other and to have homoscedasticity, or homogeneity of variance of variables. The basic multiple regression equation is: 
$\hat{Y}=b_{0}+b_{1} X_{1+} b_{2} X_{2}+b_{3} X_{3}+b_{4} X_{4}+b_{5} X_{5}$

- $\quad$ where $b_{0}$ is the intercept, and

- $\quad b_{1}, b_{2}, b_{3}, b_{4}$, or $b_{5} \quad$ - are coefficients measuring the estimated change in $\hat{Y}$ corresponding to 1 unit change in $\mathrm{X}_{1}, \mathrm{X}_{2}, \mathrm{X}_{3}, \mathrm{X}_{4}$, or $\mathrm{X}_{5}$ when all other independent variables are held constant (David et al., 2017).

For building the best fitting regression model, the "backward elimination model" was chosen, that first evaluates the full regression model containing all independent variables, and then eliminates variables identified as redundant or are multi-collinear, until finding the best-fitting model, under the assumption that the model does not have heteroscedasticity problem.

\section{Results}

\subsection{Questionnaires Results}

The filled-in questionnaires by respondents have been received within two weeks from the sending date, with a response rate of 90 percent, or 18 responded questionnaires out of the total number of 20 , out of which 99.2 percent are usable responses since one respondent answered only the 7 questions.

Results on Part I-Introductory questions, revealed general information about the respondents, presented in Table 1.

Table 1. Introductory questions

\begin{tabular}{|c|c|c|c|c|}
\hline Summary of respondents' profiles & Frequency & Percent & $\begin{array}{c}\text { Valid } \\
\text { percent }\end{array}$ & $\begin{array}{c}\text { Cumulative } \\
\text { percent }\end{array}$ \\
\hline \multicolumn{5}{|l|}{ Sex } \\
\hline Male & 8 & 44 & 44 & 44 \\
\hline Female & 10 & 56 & 56 & 100 \\
\hline TOTAL & 18 & 100 & 100 & \\
\hline \multicolumn{5}{|l|}{ Age group } \\
\hline $25-34$ & 1 & 6 & 6 & 6 \\
\hline $35-44$ & 11 & 61 & 61 & 67 \\
\hline $45-54$ & 6 & 33 & 33 & 100 \\
\hline $55-64$ & 0 & 0 & 0 & 100 \\
\hline TOTAL & 18 & 100 & 100 & \\
\hline \multicolumn{5}{|l|}{ Educational background } \\
\hline Bachelor's Degree (BA, BSc) & 3 & 17 & 17 & 17 \\
\hline Postgraduate Degree (MA, MSc, MBA) & 9 & 50 & 50 & 67 \\
\hline PhD & 6 & 33 & 33 & 100 \\
\hline TOTAL & 18 & 100 & 100 & \\
\hline \multicolumn{5}{|l|}{ Working experience with current employer } \\
\hline $0-5$ & 0 & 0 & 0 & 0 \\
\hline $5-10$ & 1 & 6 & 6 & 6 \\
\hline $10-15$ & 7 & 39 & 39 & 44 \\
\hline $15-30$ & 10 & 56 & 56 & 100 \\
\hline 30 and over & 0 & 0 & 0 & 100 \\
\hline TOTAL & 18 & 100 & 100 & \\
\hline
\end{tabular}

Source: Own. 


\section{Macrothink}

International Finance and Banking

ISSN 2374-2089

2021, Vol. 8, No. 1

Concerning results on questions from Part II-Factors that determine the environment for financial inclusion, results from all indicator scores are grouped in 4 groups: from 75-100 (identified as main enablers), from 50-74 (potential enablers), from 25-40 (potential barriers), from 0-24 (main barriers), identifying which indicators act as main enablers and main barriers to the environment of financial inclusion, as well as which indicators could be potential enablers /or potential barriers to financial inclusion. Results are summarized in Table 2.

Table 2. Enablers and barriers to the environment for financial inclusion in North Macedonia

\begin{tabular}{|c|c|c|c|c|c|c|c|}
\hline \multicolumn{2}{|l|}{ Main enablers } & \multicolumn{2}{|l|}{ Potential enablers } & \multicolumn{2}{|l|}{$\begin{array}{l}\text { Potential } \\
\text { barriers }\end{array}$} & \multicolumn{2}{|l|}{ Main barriers } \\
\hline scores above 75 & & scores 50-74 & & scores $25-48$ & & scores below 25 & \\
\hline 1) GOVERNMENT & 55 & & & & & & \\
\hline AND POLICY & & & & & & & \\
\hline $\begin{array}{l}\text { 1.3) Incentives for } \\
\text { digitization and } \\
\text { emerging technologies }\end{array}$ & 92 & $\begin{array}{l}\text { 1.2) Promotion of } \\
\text { literacy and capability }\end{array}$ & 50 & & & $\begin{array}{l}\text { 1.1) Broad } \\
\text { strategies for } \\
\text { financial inclusion }\end{array}$ & 33 \\
\hline $\begin{array}{l}\text { 2) STABILITY AND } \\
\text { INTEGRITY }\end{array}$ & 78 & & & & & & \\
\hline 2.1) Market entry & 81 & & & $\begin{array}{l}2.4) \\
\text { Supervisory } \\
\text { capacity }\end{array}$ & 44 & & \\
\hline $\begin{array}{l}\text { 2.2) Ongoing } \\
\text { requirements }\end{array}$ & 92 & & & & & & \\
\hline $\begin{array}{l}\text { 2.3) Customer due } \\
\text { diligence }\end{array}$ & 100 & & & & & & \\
\hline $\begin{array}{l}\text { 2.5) Commitment to } \\
\text { cybersecurity }\end{array}$ & 60 & & & & & & \\
\hline 3) PRODUCTS AND & 44 & & & & & & \\
\hline OUTLETS & & & & & & & \\
\hline $\begin{array}{l}\text { 3.2) Credit portfolios for } \\
\text { middle and low-income } \\
\text { customers }\end{array}$ & 100 & $\begin{array}{l}\text { 3.3) Emerging } \\
\text { services }\end{array}$ & 50 & $\begin{array}{l}3.1 \text { ) } \\
\text { Accounts at } \\
\text { financial } \\
\text { institutions } \\
\text { and e-money } \\
\text { 3.5) Financial } \\
\text { outlets } \\
\text { (Agents, } \\
\text { merchants } \\
\text { and } \\
\text { electronic } \\
\text { channels) }\end{array}$ & 38 & $\begin{array}{l}\text { 3.4) Inclusive } \\
\text { insurance }\end{array}$ & 0 \\
\hline 4) CONSUMER & 86 & & & & & & \\
\hline PROTECTION & & & & & & & \\
\hline $\begin{array}{l}\text { 4.2) Inclusive Insurance } \\
\text { users }\end{array}$ & 100 & $\begin{array}{l}\text { 4.1) Financial services } \\
\text { users }\end{array}$ & 67 & & & & \\
\hline $\begin{array}{l}\text { 4.3) Data privacy and } \\
\text { cybercrime protection }\end{array}$ & 91 & & & & & & \\
\hline & 66 & & & & & & \\
\hline INFRASTRUCTURE & & & & & & & \\
\hline $\begin{array}{l}\text { 5.1) Payments } \\
\text { infrastructure }\end{array}$ & 84 & & & $\begin{array}{l}\text { 5.2) Digital } \\
\text { IDs }\end{array}$ & 25 & & \\
\hline 5.3) Connectivity & 77 & & & & & & \\
\hline $\begin{array}{l}\text { 5.4) Credit information } \\
\text { and other data-sharing } \\
\text { systems }\end{array}$ & 79 & & & & & & \\
\hline
\end{tabular}




\section{Macrothink}

Questionnaires results were utilized for performing a comparative analysis to determining the current position of our country to the World average and different regions by grouping the results of the sample countries in regions by income group.

The overall score for the environment for financial inclusion in our country is 60 out of 100 , being above the World average, but having a lower value than the High-Income countries.

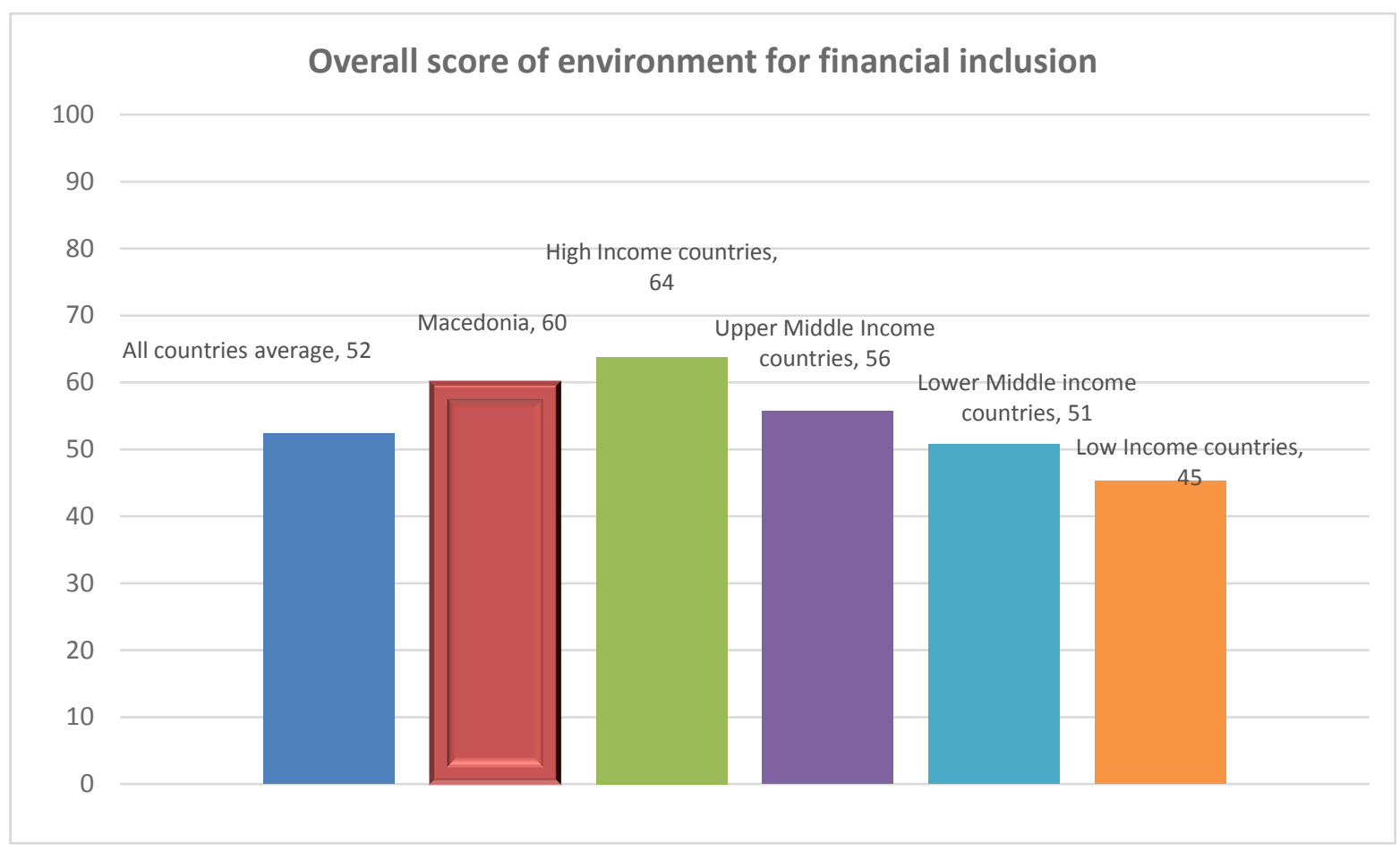

Figure 1.

Source: EIU (2018) and own.

As regards the scores for each domain determining the environment for financial inclusion, the comparative data for our country with the World average has shown that our country is in line with the level of World development in the domain "Government and Policy Support", while having a higher level of developed domains in terms of "Consumer Protection", "Stability and Integrity" and "Infrastructure". However, as concerns the "Products and Outlets" domain, our country has less developed indicators than the World average. 


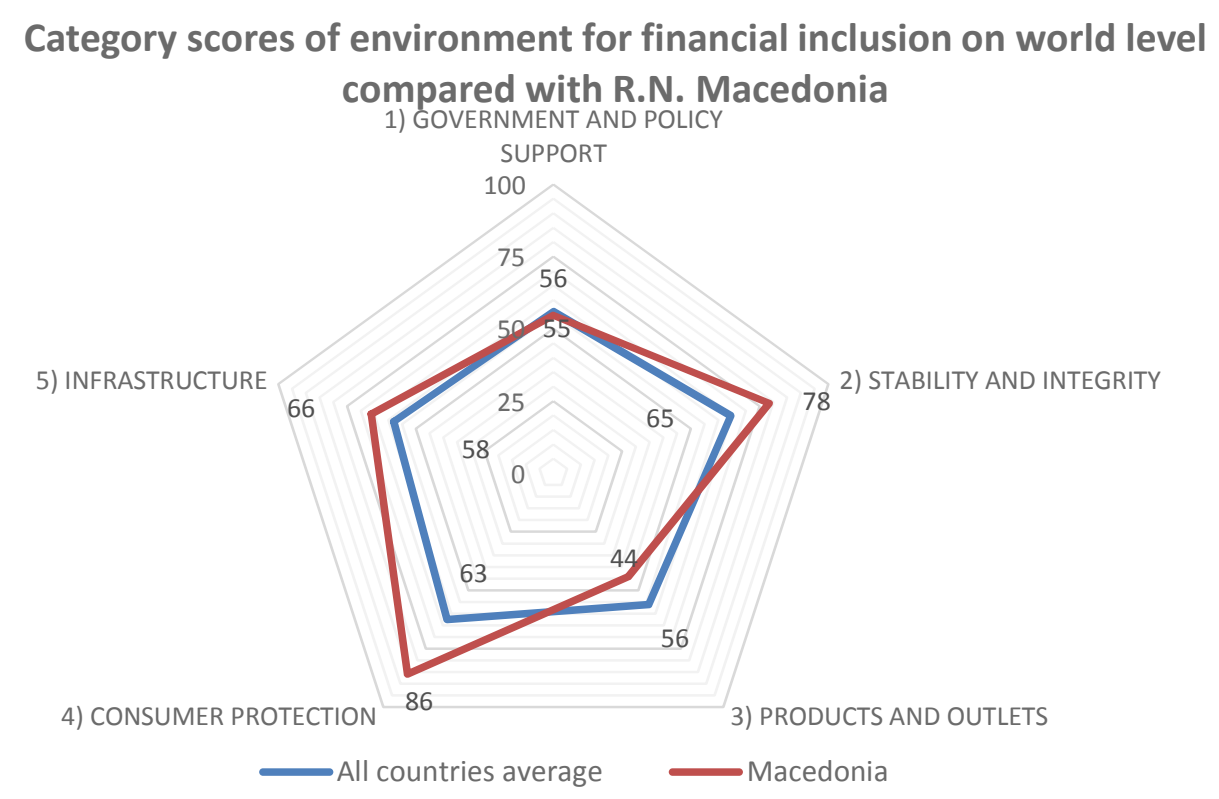

Figure 2.

Source: EIU (2018) and own.

If data for our country are compared with groups of countries by level of income it can be noticed that our country has lower scores in the "Government and Policy" domain (55) than High-Income countries (having a score of 65) while in line with Upper-Middle Income group where our country is also categorized. As regards the "Infrastructure" domain, our country has also a lower score (63) than High-Income countries (having a high 75) and is in line with the Upper-Middle Income group. Our country has high scores for "Consumer Protection" and "Stability and Integrity", even slightly higher than the "High-Income group. However, our country has even the lowest score from all income groups for the domain "Products and Outlets", which is a sign for the additional examination which are the main barriers within this domain that mostly determine this low score. 
Category scores of environment for financial inclusion by income group countries and R.N. Macedonia

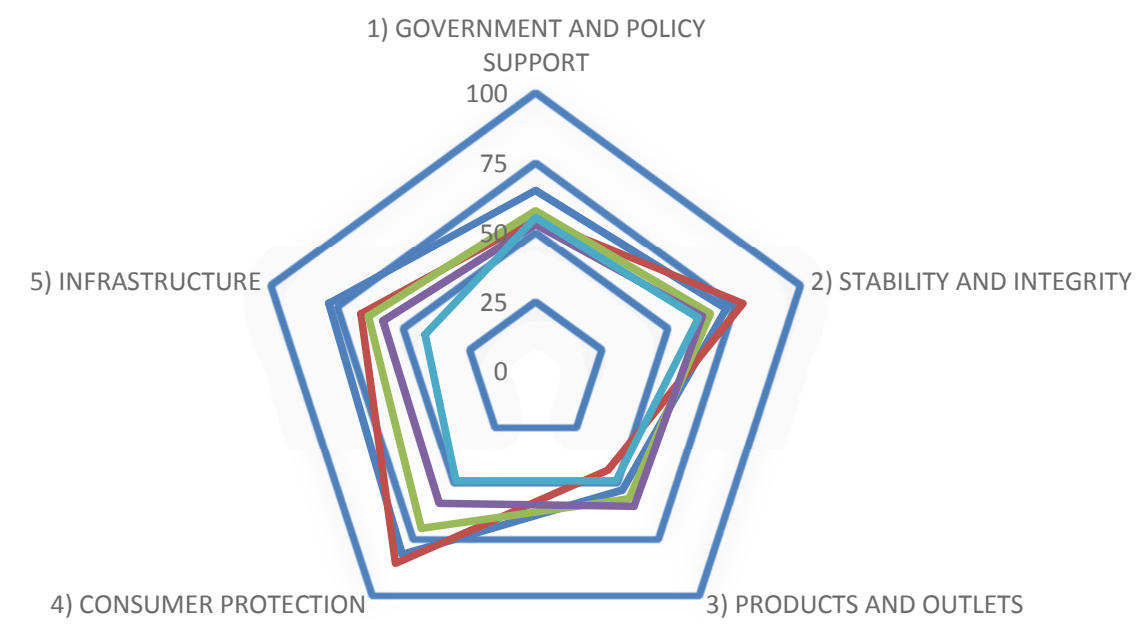

Figure 3.

Source: EIU (2018) and own.

\subsection{Results from the Regression Analysis}

To examine the relationship between the identified enablers \& barriers versus overall financial inclusion, as the $2^{\text {nd }}$ additional research objective of this study, a multiple regression analysis was performed. It is assumed that each indicators domain (as independent variables) are normally expected to be related to the overall score for financial inclusion since the dependent variable is a function of all independent variables, but the argument behind applying the multiple regression lies in the political risk factor applied to the overall score for financial inclusion, which could have a different impact on each indicator domain, and thus reflecting on the overall inclusion score differently.

To examine the overfitting risk, first scatterplots were be performed for each independent \& dependent variable set. 

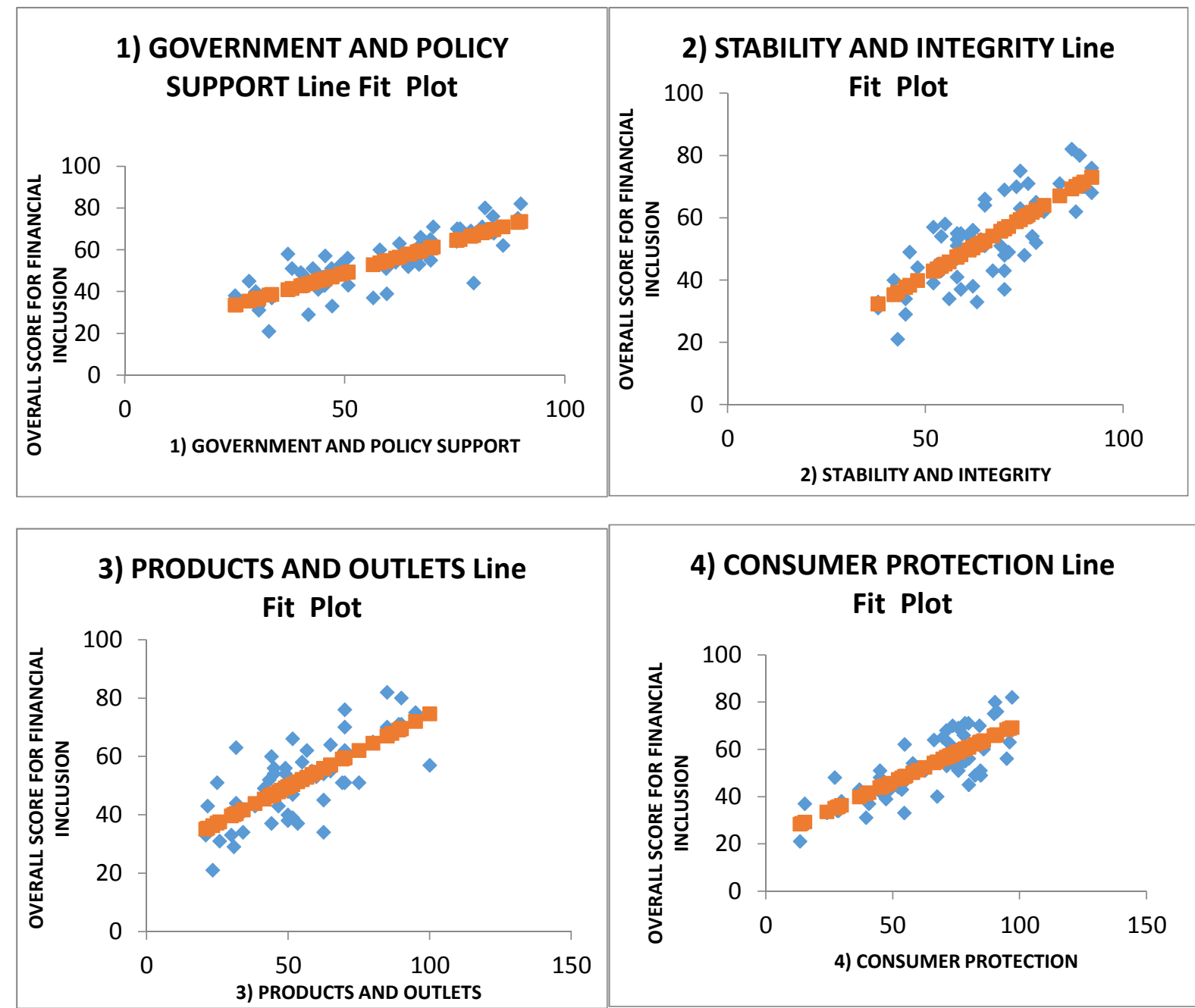

\section{4) CONSUMER PROTECTION Line}

Fit Plot

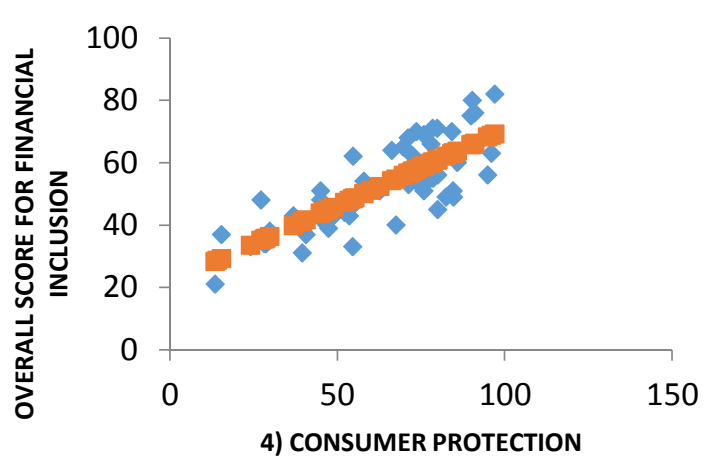

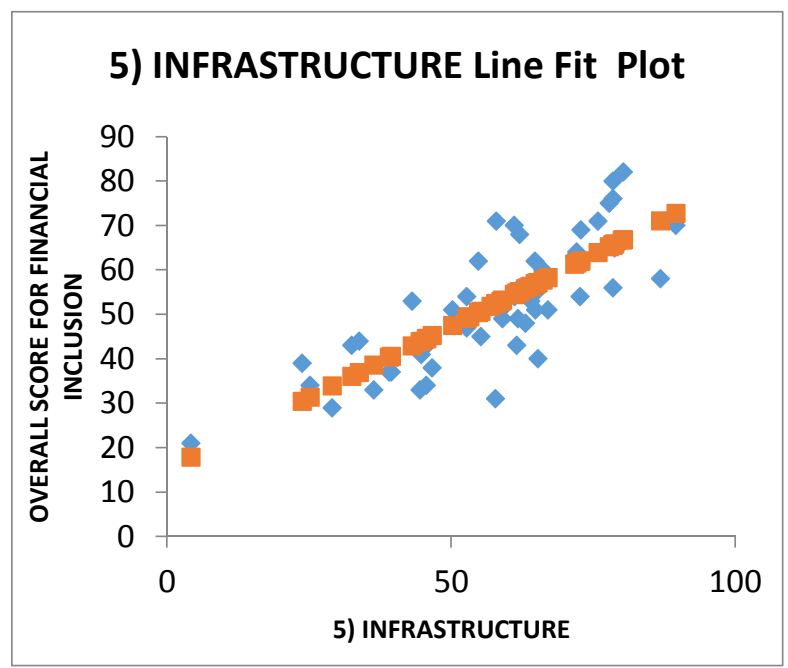

Figure 4. Scatterplots of each independent vs dependent variable

Source: Own. 


\section{MInstitute Macrothink}

The summary of scatterplots results show that:

- Financial inclusion (y) appears highly correlated with Government and Policy Support (x1)

- $\quad$ Financial inclusion (y) appears highly correlated with Stability and Integrity (x2)

- $\quad$ Financial inclusion (y) appears highly correlated with Products and Outlets (x3)

- Financial inclusion (y) appears highly correlated with Consumer Protection (x4)

- $\quad$ Financial inclusion (y) appears highly correlated with Infrastructure (x5)

An additional argument that supports the conclusion that all independent variables are highly correlated with $\mathrm{Y}$ is provided by the results in Table 3 representing the high correlation coefficients between each independent variable and dependent variable, while at the same time the correlation coefficients amongst independent variables are all far below 0,90 which indicates that variables are not correlated between each other.

Table 3. Correlation between independent variables and dependent variable and amongst independent variables

\begin{tabular}{|c|c|c|c|c|c|c|}
\hline & $\begin{array}{l}\text { OVERALL } \\
\text { SCORE FOR } \\
\text { FINANCIAL } \\
\text { INCLUSION } \\
\end{array}$ & $\begin{array}{l}\text { 1) } \\
\text { GOVERNMENT } \\
\text { AND POLICY } \\
\text { SUPPORT } \\
\end{array}$ & $\begin{array}{l}\text { 2) } \\
\text { STABILITY } \\
\text { AND } \\
\text { INTEGRITY }\end{array}$ & $\begin{array}{l}\text { 3) } \\
\text { PRODUCTS } \\
\text { AND } \\
\text { OUTLETS }\end{array}$ & $\begin{array}{l}\text { 4) CONSUMER } \\
\text { PROTECTION }\end{array}$ & $\begin{array}{l}\text { 5) } \\
\text { INFRASTRUCTURE }\end{array}$ \\
\hline $\begin{array}{l}\text { OVERALL SCORE FOR } \\
\text { FINANCIAL } \\
\text { INCLUSION }\end{array}$ & 1 & & & & & \\
\hline $\begin{array}{l}\text { 1) GOVERNMENT AND } \\
\text { POLICY SUPPORT }\end{array}$ & 0.8174567 & 1 & & & & \\
\hline $\begin{array}{l}\text { 2) STABILITY AND } \\
\text { INTEGRITY }\end{array}$ & 0.7593401 & 0.689118331 & 1 & & & \\
\hline $\begin{array}{l}\text { 3) PRODUCTS AND } \\
\text { OUTLETS }\end{array}$ & 0.7426588 & 0.557675565 & 0.49639227 & 1 & & \\
\hline $\begin{array}{l}\text { 4) CONSUMER } \\
\text { PROTECTION }\end{array}$ & 0.7962841 & 0.534268781 & 0.40026395 & 0.49301171 & 1 & \\
\hline 5) INFRASTRUCTURE & 0.7967561 & 0.456538328 & 0.50385769 & 0.50953238 & 0.72437109 & 1 \\
\hline
\end{tabular}

Also, simple linear regressions have been conducted for each independent/dependent variable pair, to check the regression parameters and validate the previous arguments. Summary data of the simple linear regressions between each independent variable and the dependent variable set is presented in Table 4, where it is evident that all independent variables contribute to the model, evidenced by high values of $F$, the p-values are far below the threshold of 0.05 (or 95\% confidence level) imposing that all variables are statistically significant for the multi regression model, relatively low Standard errors and relatively high values of R Square (adj) explaining the degree to which the independent variable explains the variation of dependent variable $\mathrm{Y}$. The independent variable having the best parameters is $\mathrm{X} 1$ 


\section{Macrothink Institute"}

(GOVERNMENT AND POLICY SUPPORT) having the highest R Square (adj) $=0.662$ meaning that $\mathrm{X} 1$ explains $66,2 \%$ of the variation in $\mathrm{Y}$, followed by the highest $\mathrm{F}$ explaining the significance of $\mathrm{X} 1$ to $\mathrm{Y}$, very low level of $\mathrm{p}$-value confirming that this variable is statistically significant to the model, and lowest Standard error (8.04).

Table 4. Summary data of simple linear regressions

\begin{tabular}{|c|c|c|c|c|c|c|c|c|c|}
\hline & $\mathbf{F}$ & p-value & Stand. error & $\begin{array}{l}\text { R Square } \\
\text { (adj) }\end{array}$ & $\mathrm{X} 1$ & $\mathrm{X} 2$ & $\mathbf{X 3}$ & $\mathrm{X} 4$ & X5 \\
\hline 1) GOVERNMENT & 108.7661017 & $1.51322 \mathrm{E}-14$ & 8.040963119 & 0.662091803 & OK & & & & \\
\hline \multicolumn{10}{|l|}{ AND POLICY } \\
\hline \multicolumn{10}{|l|}{ SUPPORT (X1) } \\
\hline 2) STABILITY AND & 73.53821721 & $1.1752 \mathrm{E}-11$ & 9.083848454 & 0.568756713 & & OK & & & \\
\hline \multicolumn{10}{|l|}{ INTEGRITY (X2) } \\
\hline 3) PRODUCTS AND & 66.41265432 & 5.66667E-11 & 9.348759473 & 0.543237376 & & & OK & & \\
\hline \multicolumn{10}{|l|}{ OUTLETS (X3) } \\
\hline 4) CONSUMER & 93.56859455 & $2.18821 \mathrm{E}-13$ & 8.444872183 & 0.627291971 & & & & OK & \\
\hline \multicolumn{10}{|l|}{ PROTECTION (X4) } \\
\hline $\begin{array}{l}\text { 5) INFRASTRUCTURE } \\
\text { (X5) }\end{array}$ & 93.87240688 & $2.06885 \mathrm{E}-13$ & 8.436192486 & 0.628057721 & & & & & OK \\
\hline
\end{tabular}

To check if there is a multicollinearity issue in the full regression model, and choose the best fitting model for our predictions, multivariate regression analysis has been conducted for the full model - Y (Financial inclusion) versus all independent variables X1, X2, X3, X4, X5, and the summary of results are presented in Table 5.

Table 5. Multivariate regression analysis of (Y) vs X1, X2, X3, X4, X5

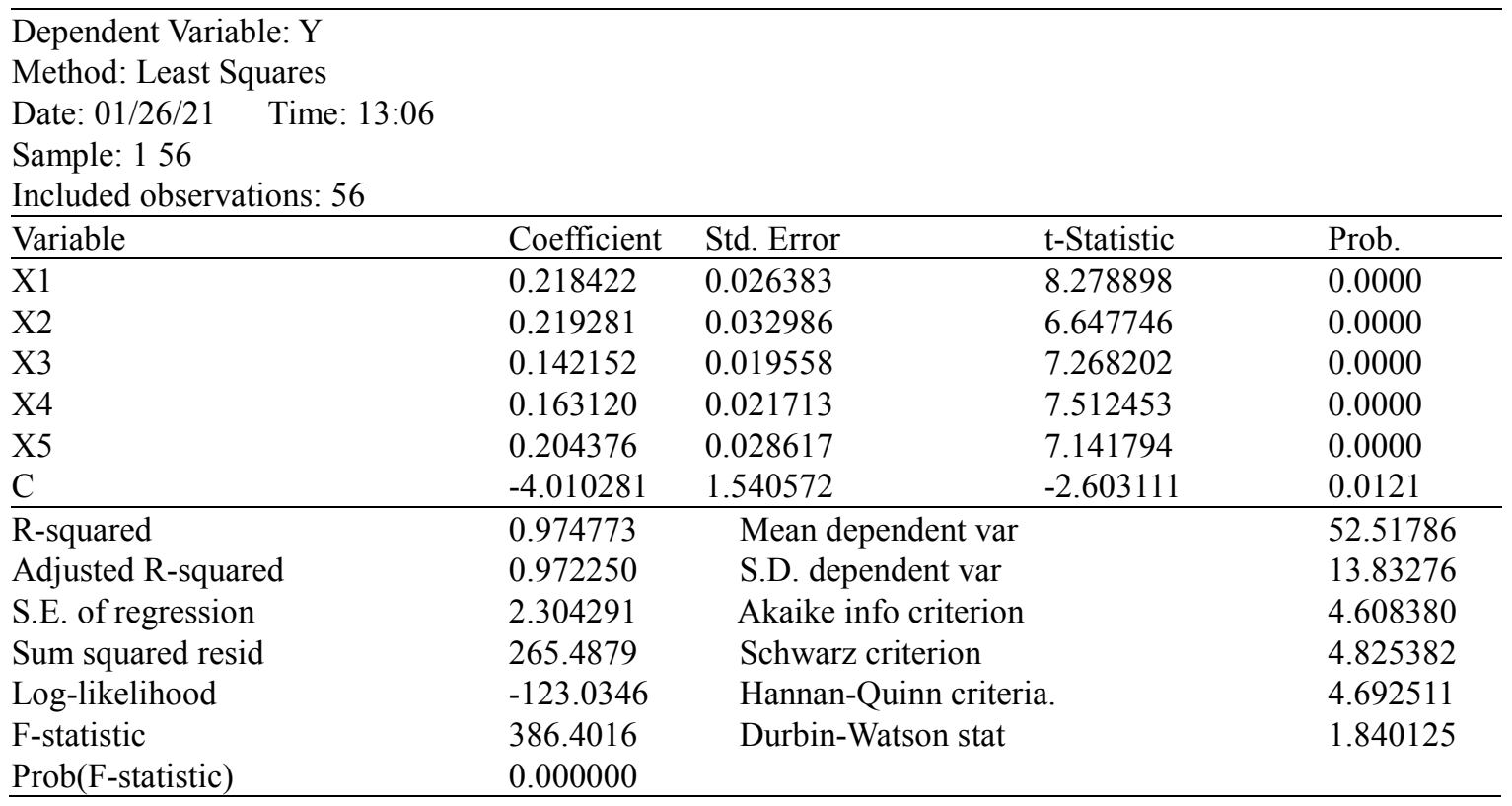




\section{Ml Macrothink}

Table 5 results show very high $\mathrm{R}$ square $(\mathrm{adj})=0.972$ confirming a very high contribution of the predictor variables to $\mathrm{Y}$ of high $97.2 \%$, which is also much higher than the values of individual $\mathrm{R}$ square (adj) in the simple linear regression models (Table 4) showing the lower contribution of each independent variable to the model. The p-value of the overall model (0.0000) together with the very high value of F-statistic (386.4) shows that the model is statistically significant. The F- statistic value of the overall model is higher than F-statistic values in the simple linear regressions which show that the independent variables have a better joint effect into $\mathrm{Y}$ than individually. Also, the p-values of each independent variable of (0.0000) also show that each independent variable is statistically significant for the overall model.

Table 6. Variance inflation factors

\begin{tabular}{|c|c|c|c|}
\hline \multicolumn{4}{|c|}{ Variance Inflation Factors } \\
\hline \multicolumn{4}{|c|}{ Date: 01/26/21 Time: 13:08 } \\
\hline \multicolumn{4}{|l|}{ Sample: 156} \\
\hline \multicolumn{4}{|c|}{ Included observations: 56} \\
\hline & Coefficient & Uncentered & Centered \\
\hline Variable & Variance & VIF & VIF \\
\hline $\mathrm{X} 1$ & 0.000696 & 25.39989 & 2.433600 \\
\hline $\mathrm{X} 2$ & 0.001088 & 50.36101 & 2.183928 \\
\hline $\mathrm{X} 3$ & 0.000383 & 14.27066 & 1.679165 \\
\hline $\mathrm{X} 4$ & 0.000471 & 22.19222 & 2.471328 \\
\hline $\mathrm{X} 5$ & 0.000819 & 31.71650 & 2.490851 \\
\hline $\mathrm{C}$ & 2.373363 & 25.03096 & NA \\
\hline
\end{tabular}

The multi-collinearity of the independent variables or high correlation amongst independent variables is examined through the values of VIF's and a summary of results are presented in Table 6, where it is evident that all VIF values are below the value of 5.0, confirming that the independent variables are not correlated, also presented in Table 3 where the correlation coefficients amongst independent variables were all below 0,90 which indicates that variables are not correlated between each other.

To examine the heteroscedasticity, first, a residual analysis is conducted for the multiple regression model, which results show that it is very little or no pattern in the relationship between residuals and predicted value of $\mathrm{Y}$, as well as between residuals and the values of independent variables, presented in the scatterplots (Figures 5). 

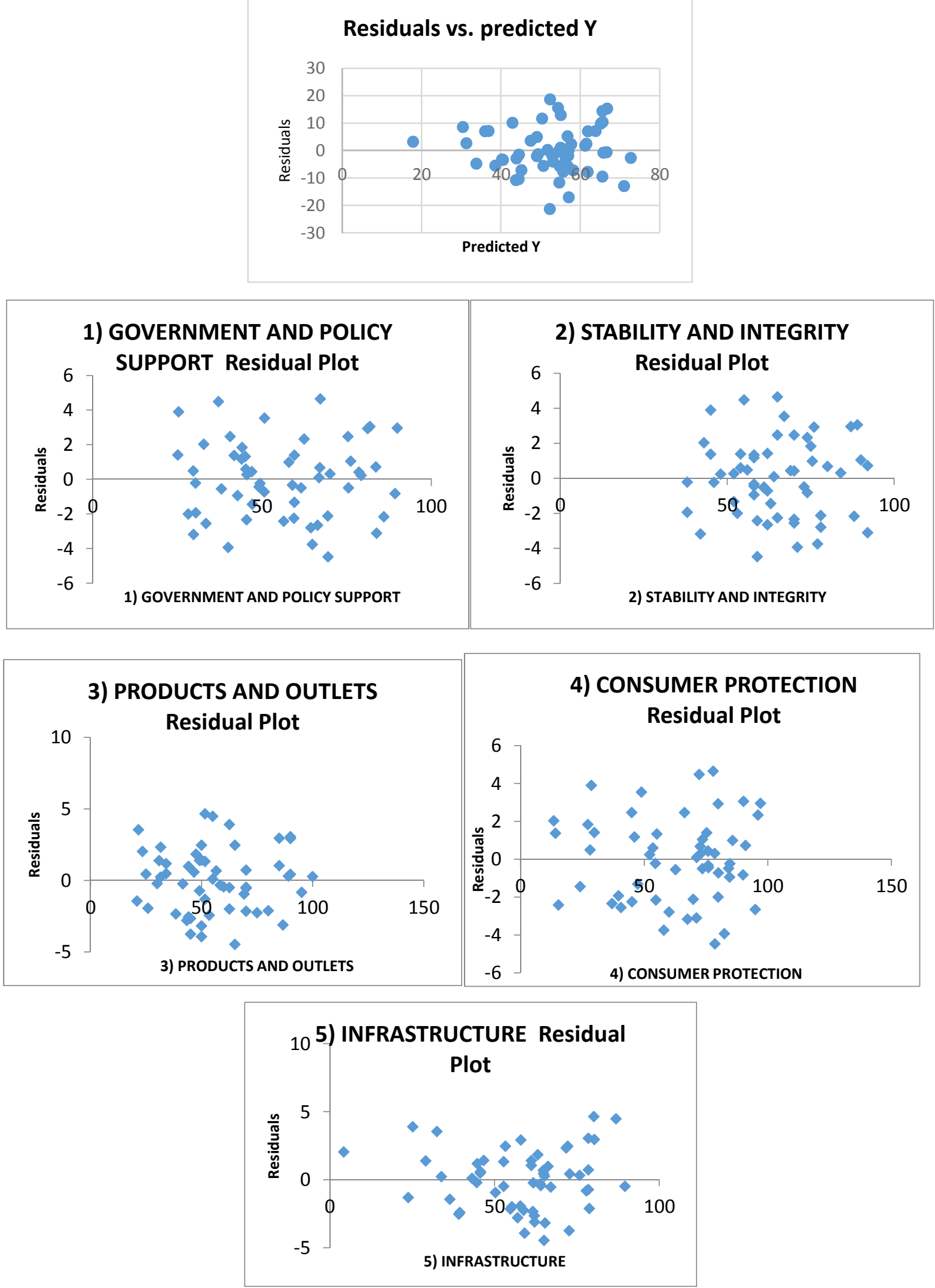

Figure 5. Scatterplots of residuals vs. predicted Y and independent variables Source: own. 


\section{Macrothink}

To validate our assumptions, the Breusch-Pagan-Godfrey and Jarque-Bera tests are conducted for the multiple regression model, and results are summarized in Table 7 and Figure 6.

Table 7. Breusch-Pagan-Godfrey test

\begin{tabular}{|c|c|c|c|c|}
\hline \multicolumn{5}{|c|}{ Heteroskedasticity Test: Breusch-Pagan-Godfrey } \\
\hline F-statistic & 0.320029 & \multicolumn{2}{|c|}{ Prob. F(5,50) } & 0.8986 \\
\hline Obs*R-squared & 1.736586 & \multicolumn{2}{|c|}{ Prob. Chi-Square(5) } & 0.8843 \\
\hline Scaled explained SS & 0.960604 & \multicolumn{2}{|c|}{ Prob. Chi-Square(5) } & 0.9657 \\
\hline \multicolumn{5}{|l|}{ Test Equation: } \\
\hline \multicolumn{5}{|c|}{ Dependent Variable: RESID^2 } \\
\hline \multicolumn{5}{|l|}{ Method: Least Squares } \\
\hline Date: $01 / 26 / 21$ & \multicolumn{4}{|c|}{ Time: 13:07 } \\
\hline \multicolumn{5}{|l|}{ Sample: 156} \\
\hline \multicolumn{5}{|c|}{ Included observations: 56} \\
\hline Variable & Coefficient & Std. Error & t-Statistic & Prob. \\
\hline $\mathrm{C}$ & 1.953441 & 3.889798 & 0.502196 & 0.6177 \\
\hline $\mathrm{X} 1$ & -0.019685 & 0.066615 & -0.295506 & 0.7688 \\
\hline $\mathrm{X} 2$ & 0.031587 & 0.083286 & 0.379255 & 0.7061 \\
\hline $\mathrm{X} 3$ & -0.018964 & 0.049382 & -0.384020 & 0.7026 \\
\hline $\mathrm{X} 4$ & -0.019728 & 0.054824 & -0.359841 & 0.7205 \\
\hline X5 & 0.071233 & 0.072255 & 0.985858 & 0.3289 \\
\hline R-squared & 0.031010 & \multicolumn{2}{|c|}{ Mean dependent var } & 4.740855 \\
\hline Adjusted R-squared & -0.065888 & \multicolumn{2}{|c|}{ S.D. dependent var } & 5.635422 \\
\hline S.E. of regression & 5.818115 & \multicolumn{2}{|c|}{ Akaike info criterion } & 6.460787 \\
\hline Sum squared resid & 1692.523 & \multicolumn{2}{|c|}{ Schwarz criterion } & 6.677789 \\
\hline Log likelihood & -174.9020 & \multicolumn{2}{|c|}{ Hannan-Quinn criter. } & 6.544918 \\
\hline F-statistic & 0.320029 & \multicolumn{2}{|c|}{ Durbin-Watson stat } & 2.111841 \\
\hline $\operatorname{Prob}(\mathrm{F}$-statistic) & 0.898617 & & & \\
\hline
\end{tabular}

As regards the heteroscedasticity issue, the Breusch-Pagan-Godfrey test shows that the p-value (0.898) is above 0.05 and it can be concluded that there is no heteroscedasticity of errors in regression, or the variance of errors is homogeneous.

Also, the results of the histogram of the observations for residuals show that the Jarque-Bera probability $(0.929)$ is above 0.05 , demonstrating that the data is normally distributed. 


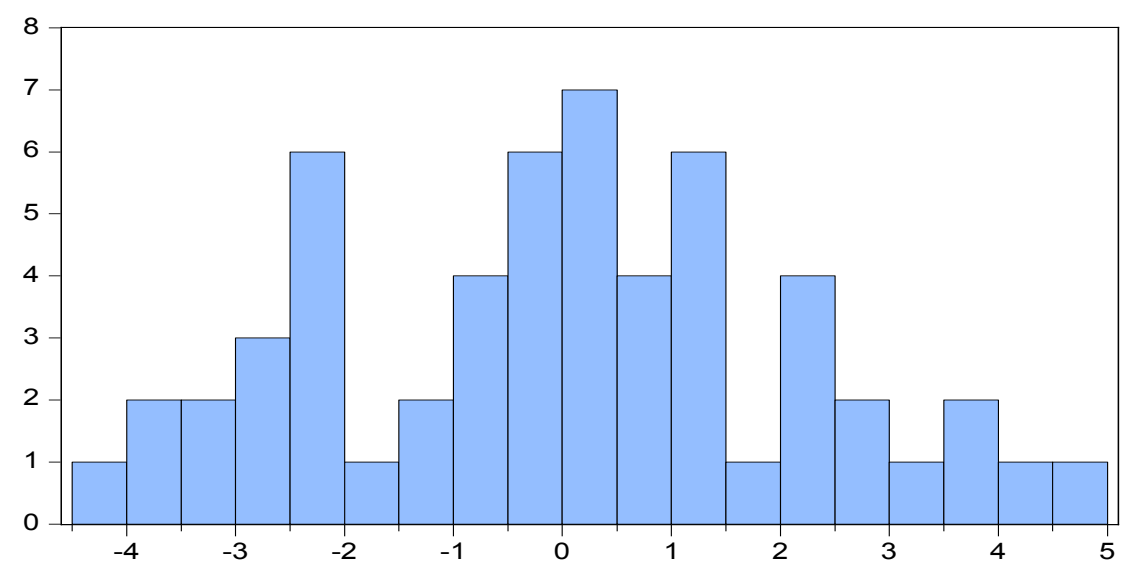

Series: Residuals

Sample 156

Observations 56

Mean

Median

4.13e-15

Maximum

Minimum

0.164985

Std. Dev. $\quad 2.197055$

Skewness $\quad 0.076838$

Kurtosis $\quad 2.387759$

Jarque-Bera $\quad 0.929728$

Probability

0.628220

Figure 6. Jarque-Bera test

Based on the results from the conducted full multiple regression model of $\mathrm{Y}$ vs $\mathrm{X} 1, \mathrm{X} 2, \mathrm{X} 3$, $\mathrm{X} 4, \mathrm{X} 5$, it can be concluded that the full model is the best-fit model because it has better coefficients than the simple linear regressions and can be used for our predictions.

The results of the multiple regression equation are:

$\hat{Y}=-4.010281+0.218422 * X_{1+} 0.219281 * X_{2}+0.142152 * X_{3}+0.163120 * X_{4}+0.204376 * X_{5}$

Evidencing that all domain factors are positively correlated with the dependent variable - the environment for financial inclusion.

\section{Conclusions and Discussion}

Results from the multiple regression analysis showed that the "Stability and Integrity" domain has the highest positive impact on the environment for financial inclusion, while the weakest factor within this group - "Supervisory capacity", according to questionnaire results refers to its technical capacities, i.e., non-application of regtech in supervision.

The second most significant contribution to the dependent variable has the "Government and policy support" which was detected as a "potential enabler" but its group score is very close to becoming a "potential barrier" (especially due to the weakest factor within this group-absence of government strategies for financial inclusion, in terms of lack of strategies for agent networks, data collection of low-middle income population, and strategies for financial and especially digital literacy).

Although the "Products and Outlets" domain has the weakest positive contribution to the dependent variable, however, questionnaires results revealed that this domain is least developed (its score falls in the "potential barrier" category) mainly due to the following identified weak areas: lack of regulation for inclusive insurance, regulation and especially infrastructure for remote accounts openings, and regulations allowing ease and breadth of operations for agents.

The "Consumer Protection" has the second-lowest positive impact on the dependent variable, 
and measured as the highest developed amongst other domains having a score falling in the "main enabler" category. However, questionnaires results revealed that the weakest area in this domain is the lack of a law/regulation that sets standards for complaints handling and resolution as well as incomplete regulation in terms of stipulating the fair treatment aspects for setting minimum standards for debt collection.

The "Infrastructure" has a relatively high positive impact on the environment for financial inclusion and is categorized as a "potential enabler", while the weakest area that reduced its score is the lack of developed Digital ID systems.

The identified weak areas within each domain are important signals where future efforts on national stakeholders should be focused on their improvement in the function of creating a more favorable environment for financial inclusion.

\subsection{Limitations from the Study}

The potential limitation of the research is seen in the non-equal representation of the countries within the used sample of 55 countries from all regions as well as income groups. Namely, the countries comprising the sample were mainly from low and middle-income countries, while a very low number of countries are representing High-Income countries in the model (only 5 countries out of the total sample of 55 countries), which is a very low representational sample of this group. Also, the Global Microscope benchmarking model (EIU, 2018) has a deep regional focus in Latin America, covering 21 countries in the region, followed by relatively high regional representation from Africa and also extending its focus in South Asia, while the very low representation from European countries (only 2 countries). This limitation can be seen as a future opportunity for expanding this research database with countries from the European region and incorporating more High-Income countries, to ensure a better representative sample for the comparative study.

\section{References}

Asli, D. K., Klapper, L., Singer, D., Ansar, S., \& Hess, J. (2018). The Global Findex Database 2017: Measuring Financial Inclusion and the Fintech Revolution. Washington DC, World Bank.

Astivia, O. L. O., \& Zumbo, B. D. (2019). Heteroskedasticity in Multiple Regression Analysis: What it is, How to Detect It, and How to Solve it with Applications in R and SPSS. Practical Assessment, Research \& Evaluation, 24(1). Retrieved from $\mathrm{http}: / /$ pareonline.net/getvn.asp? $\mathrm{v}=24 \& \mathrm{n}=1$

Bank for International Settlements. (2018). Implications of Fintech Developments for Banks and Bank's Supervisors. February, Basel, BIS.

Banque De France. (2019). National Strategy for Cashless Payment Instruments 2019-2024. Paris, National Cashless Payment Committee, Banque de France.

Committee on Payments and Market Infrastructures. (2016). Correspondent banking - final report. July. Basel, CPMI, BIS. 
David, M. L. et al. (2017). Statistics for Managers Using Microsoft Excel (8th ed.). Pearson Education Limited, Harlow, England.

Deshpande, A., Stewart, K., Lepetit, L., \& Gunashekar, S. (2017). Understanding the landscape of Distributed Ledger Technologies/Blockchain. Rand Europe. https://doi.org/10.7249/RR2223

Economist Intelligence Unit. (2018). Global Microscope 2018. The Enabling Environment for Financial Inclusion. The EIU, The Economist.

Ernest, \& Young. (2017). EY FinTech Adoption Index 2017 - The rapid emergence of FinTech. London, EY.

Ernest, \& Young. (2019). Global FinTech Adoption Index 2019. June, London, EY.

IMF. (2018). Casting Light on Central Bank Digital Currencies. IMF Staff Discussion Note, 18/08. Washington DC, IMF. https://doi.org/10.5089/9781484384572.006

IMF. (2019). Financial Access Survey 2019: Trends and Developments. Washington DC, IMF.

Kimbrough, K., \& Schindler, J. (2014). A Supply and Demand Framework of Financial Innovation. Unpublished manuscript.

KPMG. (2019). The Pulse of Fintech 2018. Biannual global analysis of investment in fintech. 13 February, KPMG International.

Kuroda, H. (2016). Innovations in Payments and FinTech: The Central Bank's Perspective. Remarks at the Forum on Payment and Settlement Systems. March 17, Tokyo, Bank of Japan.

Mas, I., \& Radcliffe, D. (2011). Mobile payments go viral: M-Pesa in Kenya. Journal of Financial Transformation, 32, 2011.

McKinsey, \& Company. (2016). Digital Finance for All: Powering Inclusive Growth in Emerging Economies. September, McKinsey \& Company.

Mnohoghitnei, I., Scorer, S., Shingala, K., \& Thew, O. (2019). Topical article: Embracing the promise of fintech. Quarterly Bulletin 2019, Q1. London, Bank of England. https://doi.org/10.5089/9781498321860.007

Nakaso, H. (2016). FinTech-Its Impacts on Finance, Economics, and Central Banking. Remarks at the University of Tokyo - Bank of Japan. Joint Conference in Tokyo on "FinTech and the Future of Money". November 18, Tokyo, Bank of Japan.

National Bank of the Republic of North Macedonia. (2020). Annual Data on Payment Operations in the Country. Payment Systems Department. Retrieved March 25, 2020, from http://www.nbrm.mk/platiezhna_statistika-en.nspx

Pereira da Silva, L. A. (2018). Fintech in EMEs: Blessing or curse? Panel remarks at CV Meeting of Central Bank Governors of CEMLA - Asuncion. 5 June, Paraguay, Bank for International Settlement. 


\section{Macrothink}

Rummel, J. F., \& Ballaine, W. C. (1963). Research Methodology in Business. New York, Harper\&Row.

Saunders, M. et al. (2003). Research Methods for Business Students (3rd ed.). Harlow, Prentice-Hall.

Schindler, J. (2017). FinTech and Financial Innovation: Drivers and Depth. Finance and Economics Discussion Series 2017-081. Washington: Board of Governors of the Federal Reserve System. https://doi.org/10.17016/FEDS.2017.081

Snee, R. D (1973). Some Aspects of Nonorthogonal Data Analysis, Part I. Developing Prediction Equations. Journal of Quality Technology, 5, 67-79. https://doi.org/10.1080/00224065.1973.11980577

United Nations. (2018). Transforming Our World: The 2030 Agenda for Sustainable Development. New York, United Nations.

Voorhies, R., Lamb, J., \& Oxman, M. (2016). Fighting poverty, profitably: Transforming the economics of payments to build sustainable, inclusive financial systems. Bill and Melinda Gates Foundation, September 2013; McKinsey Global Payments Map 2016 (2014 data).

World Bank. (2017). Distributed Ledger Technology (DLT) and Blockchain. World Bank FinTech note no 1. Washington DC, World Bank.

\section{Copyrights}

Copyright for this article is retained by the author(s), with first publication rights granted to the journal.

This is an open-access article distributed under the terms and conditions of the Creative Commons Attribution license (http://creativecommons.org/licenses/by/4.0/). 